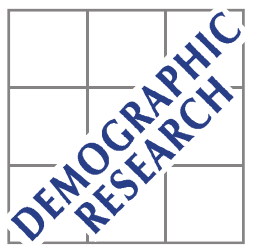

Demographic Research a free, expedited, online journal

of peer-reviewed research and commentary in the population sciences published by the Max Planck Institute for Demographic Research

Konrad-Zuse Str. 1, D-18057 Rostock · GERMANY

www.demographic-research.org

DEMOGRAPHIC RESEARCH

VOLUME 17, ARTICLE 25, PAGES 741-774

PUBLISHED 20 DECEMBER 2007

http://www.demographic-research.org/Volumes/Vol17/25/

DOI: 10.4054/DemRes.2007.17.25

Research Article

\title{
Migration and first-time parenthood: \\ Evidence from Kyrgyzstan
}

\section{Lesia Nedoluzhko}

\section{Gunnar Andersson}

Special Collection 6: Interdependencies in the Life Course, edited by Hill Kulu and Nadja Milewski.

(C) 2007 Nedoluzhko \& Andersson

This open-access work is published under the terms of the Creative Commons Attribution NonCommercial License 2.0 Germany, which permits use, reproduction \& distribution in any medium for non-commercial purposes, provided the original author(s) and source are given credit.

See http:// creativecommons.org/licenses/by-nc/2.0/de/ 


\section{Table of Contents}

$\begin{array}{lll}1 & \text { Introduction } & 742\end{array}$

$2 \quad$ Fertility and migration in post-Soviet Kyrgyzstan 743

3 Theoretical considerations on the interrelations 749

$4 \quad$ Research questions and hypotheses $\quad 751$

$5 \quad$ Further considerations and hypotheses on $\quad 752$

childbearing behavior in Kyrgyzstan

6 Data, research method, and study population 754

6.1 Covariates 757

$\begin{array}{lll}\text { 6.1.1 Migration and migration-related variables } & 757\end{array}$

$\begin{array}{lll}6.1 .2 & \text { 'Ethnicity' } & 758\end{array}$

$\begin{array}{lll}6.1 .3 & \text { Educational characteristics } & 758\end{array}$

$\begin{array}{lll}6.1 .4 & \text { Employment } & 758\end{array}$

$\begin{array}{lll}\text { 6.1.5 Marital status } & 759\end{array}$

$7 \quad$ Model results $\quad 759$

$\begin{array}{lll}7.1 & \text { Migration experience and first-birth fertility } & 761\end{array}$

7.2 Ethno-cultural differentials in first-birth behavior 763

$\begin{array}{lll}7.3 & \text { Education, employment, and first-time parenthood } & 763\end{array}$

$\begin{array}{lll}7.4 & \text { Marital status } & 764\end{array}$

$8 \quad$ Reflections $\quad 765$

9 Acknowledgments $\quad 768$

$\begin{array}{ll}\text { References } & 769\end{array}$

$\begin{array}{ll}\text { Appendix } 1 & 774\end{array}$ 


\title{
Migration and first-time parenthood: \\ Evidence from Kyrgyzstan
}

\author{
Lesia Nedoluzhko ${ }^{1}$ \\ Gunnar Andersson ${ }^{2}$
}

\begin{abstract}
This article investigates the reproductive behavior of young women and men in the post-Soviet Central Asian republic of Kyrgyzstan, focusing on the link between migration and fertility. We employ event-history techniques to retrospective data from the 'Marriage, Fertility, and Migration' survey conducted in Northern Kyrgyzstan in 2005 to study patterns in first-time parenthood. We demonstrate the extent to which internal migration is related to family formation and to the patterns of becoming a parent after resettlement. We gain deeper insights into demographic behavior by considering information on factors such as the geographical destination of migration and retrospectively stated motives for reported moves. In addition, our study reveals clear ethno-cultural differences in the timing of entry into parenthood in Kyrgyzstan.
\end{abstract}

\footnotetext{
${ }^{1}$ Max Planck Institute for Demographic Research, Rostock. E-mail: lesia.n@mail.ru

${ }^{2}$ Stockholm University, Department of Sociology. E-mail: gunnar.andersson@ sociology.su.se
} 


\section{Introduction}

Situated in Central Asia, Kyrgyzstan shares the feature of being a post-Soviet republic experiencing various aspects of post-socialist economic, social, and political transformation with that of belonging to a group of countries that has ties in common with their Turkish linguistic and Moslem cultural roots. Its majority population, the Kyrgyz, is of Asian origin, but the country also has population subgroups of European origin, most of them ethnical Russians. As do other post-socialist societies, Kyrgyzstan experiences various features of family-demographic change that may be considered part of the so called 'Second Demographic Transition'. However, as in the other Central Asian republics, its majority population still has not completed its first demographic transition, making the country a very intriguing context for a study of familydemographic dynamics. In this paper, we provide some first insights into familyformation behavior in post-Soviet Kyrgyzstan, paying particular attention to the interplay between migration and entry into parenthood among its different ethnocultural population subgroups.

Existing research on reproductive behavior and fertility in Kyrgyzstan is rather limited. A fairly well organized system of vital statistics and censuses provides general information on levels and trends in fertility, but the system appears to be underutilized: there are few publications on the topic. A particular shortcoming is the lack of specialized studies that address different specific features of the reproductive behavior in the country, such as those related to ethnic differentials in behavior and the interrelations of fertility dynamics with other life-course careers. Most issues concerning fertility in Kyrgyzstan still wait for rigorous examination. The transition to first-time parenthood is one of them, which we will examine more closely in this study by analyzing the impact of different socio-demographic factors on the propensity to become a parent. Previous studies on Kyrgyzstan have mainly employed aggregate statistics and focused on topics such as the influence of socio-economic factors and socio-economic change on general fertility (Ryspaev 1972, Kumskova 1983, Sarygulov 2001, Nedoluzhko 2003, Denisenko 2004) or ethno-regional differentials in fertility levels (Sifman 1974, Bondarskaya 1978, Jones and Grupp 1987). We, however, will use individual-level data to study the role of migration in family formation and the timing of childbirth. By looking at the reproductive behavior of migrants and non-migrants in Kyrgyzstan, we aim at gaining deeper insights into Kyrgyz first-birth behavior in general and, more specifically, into the dynamic interactions of migration and reproduction. The latter issue has been studied for many other settings, some of them covered in contributions to the present Collection of Demographic Research, but it has never been examined in the context of Kyrgyzstan. 
Our article is organized as follows. First we provide an overview of recent developments in terms of fertility and migration in Kyrgyzstan. Then we present the theory and hypotheses that have guided our analyses, and discuss our data, the study population, and the methodology we apply. We proceed to discuss the results of our study and the information on first-birth fertility dynamics that they convey. We end with some brief conclusions.

\section{Fertility and migration in post-Soviet Kyrgyzstan}

Since independence, most Soviet successor states have experienced dramatic changes in population dynamics. A noticeable feature of the post-Soviet era is rapid fertility decline. This has often been considered a response to the adverse socio-economic developments during the post-socialist period. However, many researchers also have attributed the decline to the emergence of a 'Second Demographic Transition' in former socialist countries. In Kyrgyzstan, between 1990 and 2005 total fertility decreased by some thirty percent. Nevertheless, together with Uzbekistan and Tajikistan, it still remains a pronounced high-fertility country, with a Total Fertility Rate (TFR) in 2005 of around 2.6 children per woman, a feature that rather makes it belong to a group of countries that are in their very first demographic transition. There are differences in fertility among population subgroups, however. While the native Kyrgyz generally have a high fertility, the population of European origin has a fertility that is below replacement level. Significant differences in fertility also exist across regions and different types of settlements. The TFR is higher in rural areas than it is in urban areas: 2.9 versus 2.2 . The developments of total fertility during the transition period are presented in Figure 1.

Another distinctive demographic development of most Soviet Union successor states is mass migration, which has produced large-scale changes in population compositions. In Kyrgyzstan, emigration peaked in the early 1990s when socioeconomic hardship ${ }^{3}$ and uncertainty about the future caused hundreds of thousands of people to leave the country (see Figure 2a). Not surprisingly, the emigration flows immediately following the disintegration of the Soviet Union mostly comprised Russians and other Europeans who felt an increasing unease resulting from the nationalist outlook of the Kyrgyz governments, along with economic hardship (Fletcher

\footnotetext{
${ }^{3}$ In the first five years following the break-up of the Soviet Union, the Gross Domestic Product (GDP) of Kyrgyzstan fell to below half of its pre-independence level. This was accompanied by hyperinflation, rising unemployment, and reduced real incomes, all of which led to a dramatic increase in poverty (Falkingham 2005).
} 
and Sergeyev 2002). More recent emigration flows, however, have contained an increasing share of native Kyrgyz, who are attracted by the better employment and business opportunities in the neighboring countries. Being one of the poorest ${ }^{4}$ and politically less stable post-Soviet states, Kyrgyzstan still remains a net sender of migrants. Emigration has predominantly been directed to the Russian Federation and to neighboring Kazakhstan and Uzbekistan. Among the destinations that do not belong to the group of post-Soviet countries, we mainly find Germany and Israel.

Figure 1: Total Fertility Rates of Kyrgyzstan, by type of settlement, 1990-2005

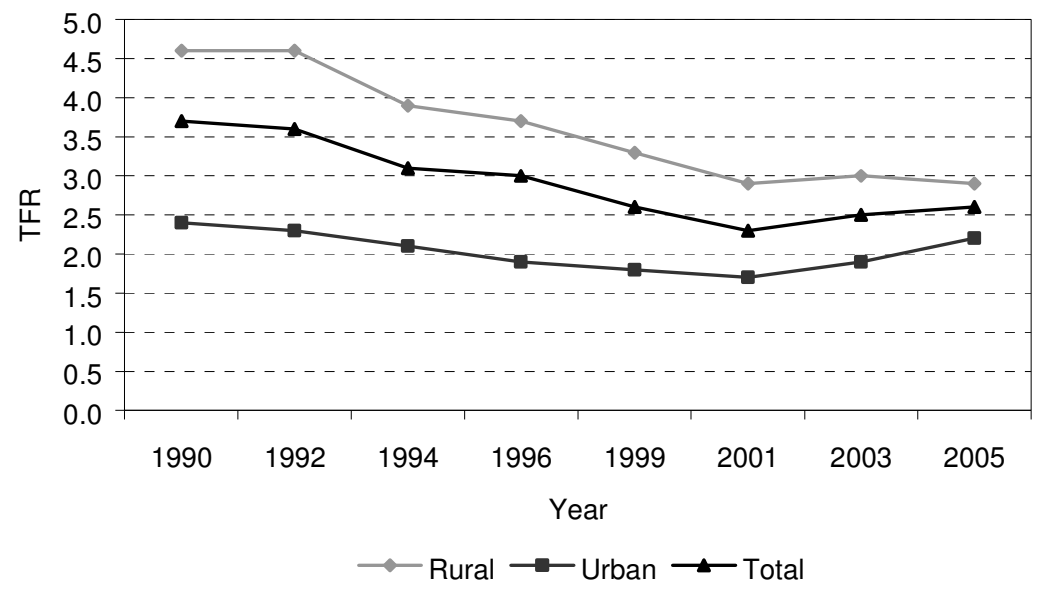

Source: National Statistical Committee of the Kyrgyz Republic.

\footnotetext{
${ }^{4}$ In 2005, the country's Gross National Income per capita amounted to $\$ 440$ (\$1870 in Purchasing Power Parity) (World Bank 2006).
} 
Figure 2a: Migration movements of Kyrgyzstan: External migration, 1991-2005

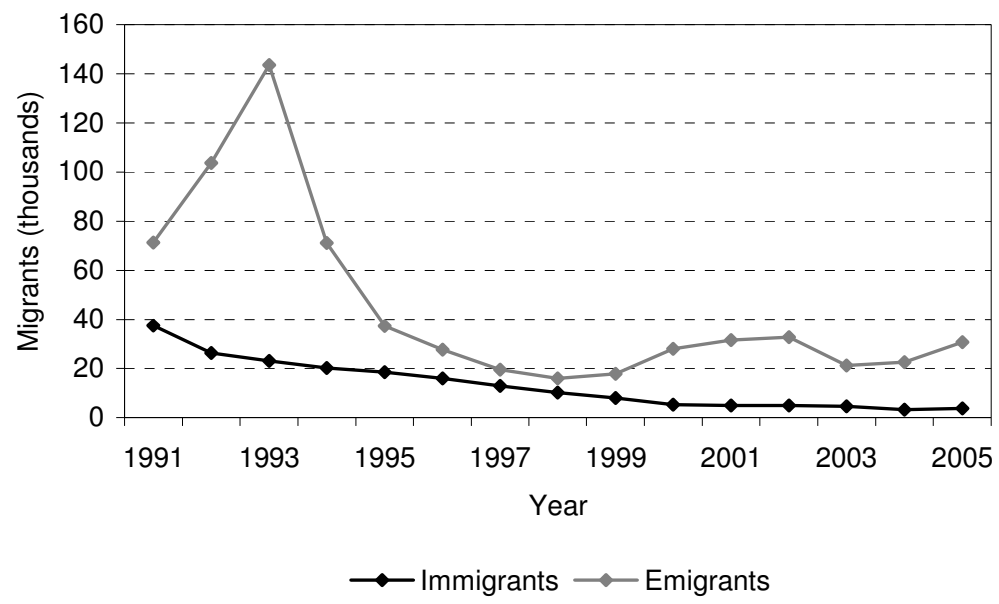

Figure 2b: Migration movements of Kyrgyzstan: Internal migration, 1996-2004

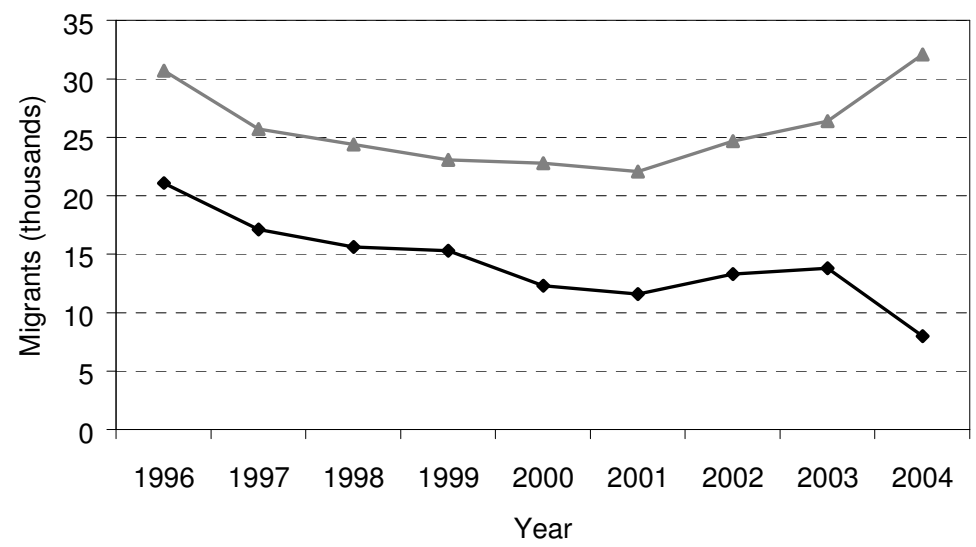

$\longrightarrow$ Moved within the same region $\longrightarrow$ Moved between regions

Source: National Statistical Committee of the Kyrgyz Republic. 
The exodus of Russians and other people of European origin has profoundly changed the ethnic composition of Kyrgyzstan's population, making it more 'Asian' in its outlook (see Figure 3). This structural change in relation to longstanding differentials in the reproductive norms and behaviors of different population subgroups - the TFR estimated from the census in 1999 was 2.9 and 3.1 for Kyrgyz and Uzbeks, respectively, and 1.3 for Russians - has sometimes even been suggested as a possible cause of aggregate fertility increase in Kyrgyzstan or areas of it (Kumskov 2002). Recent data from the National Statistical Committee partly support this assumption, indicating that the TFR in the country's capital, Bishkek, which receives the main share of internal migrants and at the same time loses Europeans through emigration, has increased in the last few years (NSC of the Kyrgyz Republic 2006).

Figure 3: Ethnic structure of the population of Kyrgyzstan, 1990 and 2005

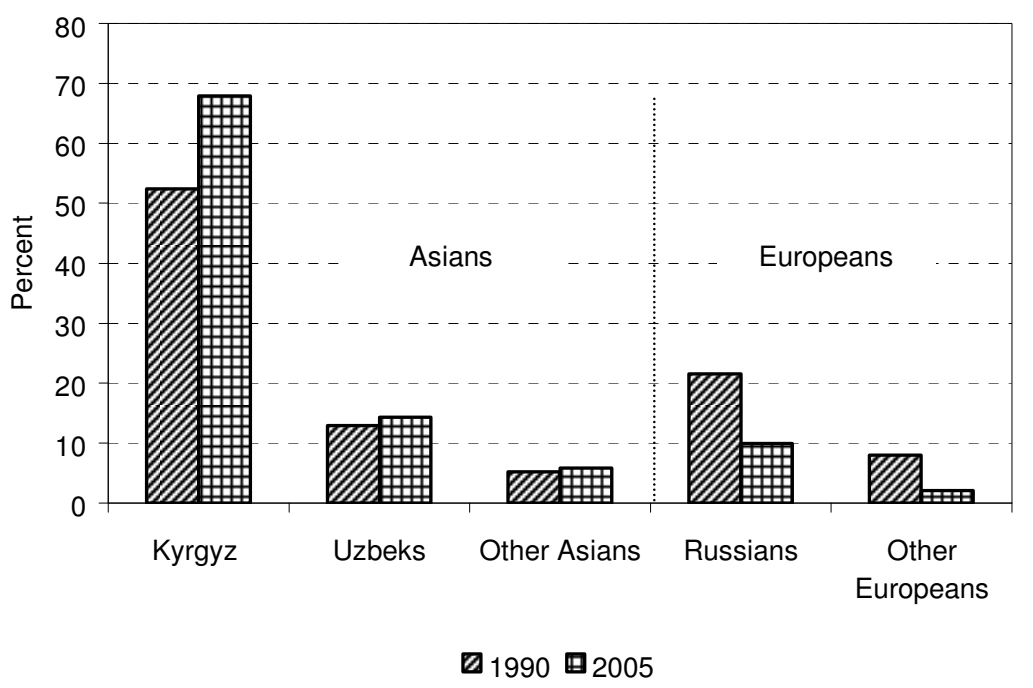

Source: National Statistical Committee of the Kyrgyz Republic.

The mass emigration in the post-Soviet era has been accompanied by high internal migration, too, a feature that is of particular interest for our study. To a large extent, the high internal migration can be explained by the unbalanced economic developments in the different regions of the country. Although the economic crisis following the disintegration of the former Soviet Union strongly affected the entire 
country, its rural areas have been much slower to recover from it than have its urban areas. Unemployment and poverty rates are higher in the rural areas - where the majority of Kyrgyzstan's population resides. Opportunities of self-employment in street and market trade, which for many have become an important income source, are limited there, too. These developments determine the main direction of internal migration: from rural to urban areas. The most popular destinations are Bishkek and the surrounding Chui province. Native Kyrgyz have moved in following the exodus of Europeans, who traditionally comprised a significant share of the population in these areas, and in recent years the region has experienced positive net migration. Meanwhile, other regions of the country have experienced negative internal net migration.

\section{Figure 4: Administrative regions of Kyrgyzstan}

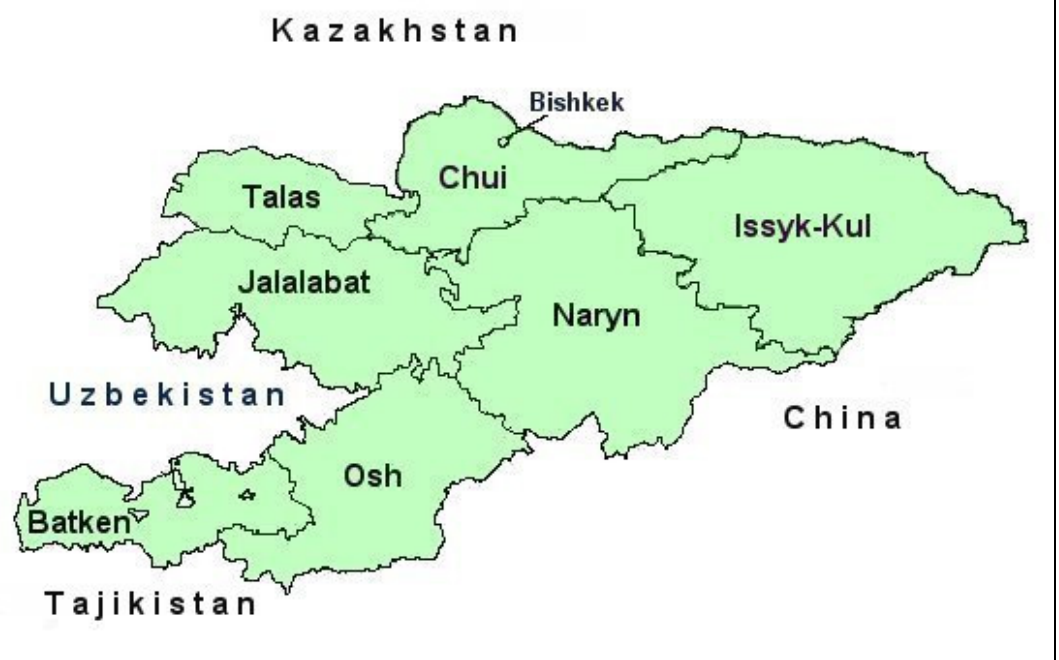

The attractiveness of the capital to internal migrants is easy to explain. Being the economic, political, and the cultural center of the country it is associated with the opportunities of a better life. Recent survey data indicate that the main causes of moving to Bishkek, as stated by internal migrants to the capital, are the opportunities of (self)employment, of higher earnings, and of better housing conditions, plus the prestige of living in the capital (Kumskova et al. 2004). An accompanying flow of migrants to the Chui province results from its vicinity to the capital. Migration to these 
areas is often perceived by migrants as permanent 'resettlement', although any resettlement, naturally, can be preceded and/or followed by further short- and long-term moves. Both Chui and the capital receive migrants from the North and South of the country, although flows from North to North are the most prominent: the provinces of Naryn and Issyk-Kul are the largest contributors of migrants to the area (Shuler and Kudabaev 2004).

Migration to the capital and its neighboring province is important, but there are certainly other types of moves as well. Migration related to family formation or to the setting up of a small business can be directed to any region or settlement in the country. Marriage-related migration is likely to be more prominent among women than among men and it has some country-specific characteristics, too. Traditional norms towards family life prescribe that a couple should live in the husband's house or in the house of his parents. Therefore, if the spousal partners come from different settlements, the woman is the more likely to migrate. In addition, a local practice of 'bride kidnapping', which can be on consensual or non-consensual grounds, makes women even more subject to marriage migration. This is a Kyrgyz custom that has reemerged following the country's independence and the frequency of bride kidnapping, both symbolic and real, seems to have increased in the post-Soviet era. A small-scale survey conducted in a rural area suggests that around one third of marriages among rural ethnic Kyrgyz stem from nonconsensual 'bride kidnappings' (Kleinbach et al. 2005).

Official data on registered moves across settlements indicate that migration between the regions of the country has been more intensive than intra-regional mobility (see Figure 2b). Moreover, since 2000, inter-regional migration has increased. Other features of post-Soviet internal migration in Kyrgyzstan are as follows:

- Women comprise the majority, close to 60 percent, of both inter- and intraregional migrants. This may partly stem from gender-specific patterns in marriage-related migration. The statistic should be taken with some caution, however, as they may be a reflection of the fact that women are more likely than men to register themselves in a new place of residence.

- The overwhelming majority of migrants are native Kyrgyz.

- Young people aged 15-34 constitute around 60 percent of migrants.

Apparently, the demographic dynamic of former Soviet Central Asia that has been most prominently addressed in the literature is that of international migration. A large number of studies have focused on the emigration of individuals of European origin, often considered the result of real or perceived discrimination (Tishkov 1994, Demakov 1997, Subbotina 1997, Nedoluzhko 2000, Kumskov 2002, Becker et al. 2003). In contrast, internal migration and other demographic responses to socio- 
economic adversity, such as the postponement of marriage formation and childbearing, have been poorly addressed (Agadjanian 1999). In the case of Kyrgyzstan, these topics have received almost no attention, although they are important. To overcome the shortcoming, a survey on young people's marital and reproductive strategies and their migration experience was carried out in 2005 in Northern Kyrgyzstan. In the present study, we use data from this survey to carry out an event-history analysis of the firstbirth dynamics of young people in post-Soviet Kyrgyzstan.

\section{Theoretical considerations on the interrelations between migration and fertility}

The demographic literature has devoted considerable attention to the dynamic interplay between fertility and migration, some of it being reflected in the Special Collection 6 of Demographic Research. Demographers and other social scientists usually test some or all of the 'assimilation', 'adaptation', 'disruption', and 'selectivity' hypotheses proposed in the literature to explain differences in fertility between non-migrants and different groups of migrants. The hypotheses have been applied to the behavior of international migrants (e.g., Stephen and Bean 1992, Singley and Landale 1998, Lindstrom and Giorguli Saucedo 2002, 2007, Milewski 2007) as well as to that of internal migrants in different countries (e.g., Goldstein and Goldstein 1984, Hervitz 1985, Kulu 2005, Chattopadhyay et al. 2006, Kulu 2006). A rigorous examination of these hypotheses requires longitudinal data on migration and childbearing, something that we have at hand in our survey of Northern Kyrgyzstan.

The assimilation and adaptation hypotheses state that fertility preferences are shaped by the cultural and socio-economic environment individuals are exposed to. In the case of internal migration, they can, for example, be applied to the changing context experienced by migrants from rural to urban areas (Farber and Lee 1984, Hervitz 1985). The assimilation hypothesis posits that fertility preferences are formed during early socialization and that they are relatively stable throughout the life; therefore, those who as adults arrive in a culturally different setting are slow to adopt the reproductive norms that are prevalent there. The process of assimilation is believed to be gradual and may take several generations to complete (Lindstrom and Giorguli Saucedo 2002). Applied to our study, the notion of early socialization suggests that first-birth behavior will be most strongly influenced by a respondent's childhood residence, and that it will resemble that of non-migrants in his or her place of origin.

The assumption of adaptation of the fertility behavior of migrants rests more strongly on factors related to the socio-economic environment of an area, and emphasizes the importance of current rather than childhood residence. Migrants are 
assumed to adjust their fertility according to the economic as well as other opportunities and constrains at their current destination. Such factors clearly differ between urban and rural settings. In a large city, living standards as well as the direct and opportunity costs of childbearing are higher than in other areas. Consequently, we expect that first-birth propensities will differ by different types of migration destinations as defined by their settlement size (e.g., Kulu et al. 2007). The process of adaptation to new socioeconomic conditions is thought to take place within a relatively short time span, since these conditions are evident as early as from the time of arrival to an area (Lindstrom and Giorguli Saucedo 2002). To study this process, it is important to consider first-birth patterns by duration since migration.

The disruption hypothesis stipulates that migration interferes with childbearing so that fertility is reduced immediately around the time of move. Such effect could arise as a result of spousal separation or stress associated with the move (Goldstein and Goldstein 1984) or owing to the desire to postpone childbearing in anticipation of a migration (Chattopadhyay et al. 2006, Kulu 2006). Unlike previously discussed assumptions, it sees the migration process itself rather than the environment either at origin or at destination as having a decisive role in determining fertility behavior. The impact of disruption is assumed to be temporary and operating for a brief period following migration. It may be stronger for those who have experienced urban-to-rural or rural-to-urban migration than for those who have moved within urban or rural settlements. In the first case, migrants need to cope not only with the difficulties of facing the new community but also with the new style of living. Hiday (1978) refers to this process as overcoming social distance.

To capture the short-term disruptive effects on fertility, we should control for time since migration. Such effects can as well be the result of various adaptation strategies. For instance, residential changes often require necessary adjustments, such as finding housing and getting a job, during which time union formation and/or childbearing may be postponed until the adjustments in question are made. Disruptive effects may also occur when migrants postpone family formation in order to gain maximum economic returns from the move (Lindstrom and Giorguli Saucedo 2002). In our study, we expect to find that those who migrate for reasons of study or work will have lower first-birth risks than non-migrants.

As a counter-argument to the hypotheses of disruption it has been suggested that it in many cases makes better sense to view migration and family formation as interrelated processes. In the case of marriage-related migration, for example, one would expect elevated rather than depressed fertility briefly after a move. Such shortterm tendency will be reinforced if women prefer to migrate before giving birth rather than vice versa. In empirical research, association patterns of this kind have been found for many different types of migrations. Andersson (2004) and Andersson and Scott 
(2005) demonstrate the role played by elevated first-birth risks of female immigrants newly arrived in Sweden. In this Special Collection 6 of Demographic Research, Milewski (2007) and Lindstrom and Giorguli Saucedo (2007) reveal similar patterns for international migrants to Germany and the U.S., respectively. Kulu (2006) demonstrates strikingly similar duration-specific profiles in the childbearing patterns of female internal migrants in Austria and Poland, and, finally, Kulu and Vikat (2007) show that such interdependencies are important also when housing moves at very short distances are considered.

Finally, the selectivity assumption suggests that migrants are selective in terms of their various characteristics (Goldstein and Goldstein 1984) and/or motivations (Macisco et al. 1970), and these, in turn, are associated with fertility. The elevated or depressed fertility of a group of migrants disappears when these characteristics are controlled for. Migrants can also be self-selected according to the reasons behind their moves (Kulu 2005). In addition, fertility preferences determine the destination of migrations: low fertility areas, such as big cities, are likely to attract people who have preferences for small families and vice versa (Farber and Lee 1984). In our analysis, we address the selectivity issue by controlling for observable socio-demographic characteristics of individuals, characteristics that may influence both migration and fertility behavior, and by controlling for the stated causes of the respondents' moves.

\section{Research questions and hypotheses}

In our study, we take the various considerations addressed above into account when testing migration-related and other hypotheses on first-birth behavior in Kyrgyzstan. We are fortunate to have access to individual-level data on migration as well as family formation histories; this is a prerequisite to test migration-related hypotheses on fertility behavior. Our survey data also provide information on the destinations and causes of each reported move and on other relevant socio-demographic characteristics of the respondents (for a description of our data, see Section 6). By studying first-birth propensities by duration since any migration, we can, for example, find out under what circumstances migration is associated with disruptive or enhancing effects on fertility. We assume that both effects matter, but that different combinations of factors are likely to strengthen one of the two while depressing the other. Both effects should be evident in behavior shortly after a migration. To detect them we need to take into account time since migration.

Our specific hypotheses on the links between migration and fertility are as follows: 
- Recent migration experience may reduce the propensity to become a parent since necessary adjustments to the new environment are likely to lead to postponed family formation. We expect a pattern of this kind to hold unless the very reason for resettlement is related to family formation.

- In contrast, migration motivated by marriage produces elevated first-birth risks during the period shortly following resettlement. We expect such enhancing effects to matter more in the life-course dynamics of women than in those of men: Our survey data show that $21 \%$ of women who migrated the first time did so for reasons of marriage, compared to only $3 \%$ of migrant men. Evidently, women often move to join their partner at his location.

- Migration motivated by study and work may deter fertility, in that it may be associated with a lower propensity to become a parent.

Accounting for the possible effect of early socialization, we expect to find that:

- The respondent's childhood place of residence may determine his or her reproductive behavior. Those born in rural settlements, where life still is more 'traditional', are likely to become parents faster than those socialized in urban areas in general, and in the capital in particular.

We also test the assumption that the fertility of migrants depends on the destination of migration, i.e., on the type of the new settlement. Considering that migration to urban and rural areas is associated with different economic as well as other opportunities and constrains and that they are likely to be driven by different motivations (Kulu 2006), we expect to find that:

- Migrants to the capital are more likely to postpone family formation, thus they are more prone to have lower first-birth risks than those who move to other types of settlements. In particular, migrants to villages are likely to have elevated first-birth risks, fuelled both by the relatively low cost of childbearing in rural areas and the strong family norms in such areas.

\section{Further considerations and hypotheses on childbearing behavior in Kyrgyzstan}

A further key dimension to consider in our analysis is that childbearing behavior may differ by respondents' ethno-cultural background. Information on this background was collected in the survey we have at hand. Ethnic differentials in demographic behavior 
are often ascribed to culture-specific differences in values, norms, and attitudes related to family issues. In a given context, they can reflect specific demographic strategies developed by ethnic minorities, such as postponement of union formation and childbearing as a means to enable a stronger focus on improving one's socio-economic position. In the case of Kyrgyzstan, differences in behavior may be a reflection of different population subgroups being at different stages of the (first and second) demographic transition. In our data, we have information on a version of 'ethnicity' that both reflects the ethnic origin of the respondents and the language they usually speak outside home. In particular, we are interested in whether respondents speak Russian or a local language when conducting their daily activities outside home. This factor serves as an indicator of the cultural environment respondents are exposed to. As in Kyrgyzstan Russian still is the language of higher education, fluency in this language partly determines individual career prospects. Communication in Russian may also be taken as evidence of some degree of 'russification' in a more general sense, perhaps indicating a more open attitude to external 'Western' influences and related to a higher degree of individual independence, gender equality, and educational and professional career orientation. All of these features, in turn, are likely to be important in terms of marriage formation and childbearing behavior. In our study, we distinguish between people of European and people of Asian origin and among the latter, between 'russified' and 'non-russified' people. This approach was first proposed in a demographic study on neighboring Kazakhstan (Agadjanian and Qian 1997). For further examples of family-demographic studies where language use is applied as a marker of ethnicity, see, e.g., Finnäs (1997), Wetherell and Plakans (1997), and Yavuz (2006).

Our hypotheses on ethno-cultural differences in first-birth behavior are as follows:

- People of European background have a lower propensity to become a parent than those of Asian origin. This is plausible due to longstanding differentials in fertility behavior and the very different positions that the two groups have in the demographic transitions. The reduced first-birth propensities of the former group can also stem from the demographic strategies it may have developed in response to its perceived precarious societal situation - sometimes perhaps even in anticipation of emigration from the country.

- 'Russified Asians' are more likely than their 'non-russified' compatriots to adjust their reproductive strategies to the possibilities and constraints of their more advanced educational and professional careers, something that may be related to later entry into parenthood in the former group. 
As regards the role played by other socio-demographic characteristics of young people in Kyrgyzstan in their childbearing behavior, we expect to find that:

- First-birth risks are lower for men than they are for women, as men become a parent at higher ages than do women.

- Higher levels of educational attainment are conducive to later family formation and thus to lower propensities to become a parent.

- Educational enrolment deters childbearing as most individuals tend to strive to complete their education before having a child.

- First-birth risks are higher among persons currently employed since those who have a job have more financial means to afford having a child, i.e., we expect that employment and fertility are positively related with each other. However, taking dominant patterns of gender relations and gender-specific childcare obligations into account, we allow for the possibility that this general expectation may hold for men but not for women.

- As most births occur in conjugal and especially in officially registered unions, married individuals have much higher first-birth risks than do non-married ones.

\section{Data, research method, and study population}

Our analysis is based on retrospective data derived from a survey named 'Marriage, Fertility, and Migration in Kyrgyzstan' and conducted in May-September 2005 among young people in urban and rural areas of Northern Kyrgyzstan. One of the motivations behind the survey was to provide data suitable to compare the demographic behavior of two distinctive population groups of the country: those of European origin and those of Asian background. This explains why the northern regions of Kyrgyzstan have been the target of the survey; these are the Chui and Issyk-Kul provinces and Bishkek, the capital (see Figure 4), where more than 90 percent of all minority Europeans reside. The same regions comprise close to 40 percent of the entire population of the country. A three-stage cluster sample was used in each of the three areas: a village/urban cluster was first selected with a probability proportional to size, then households were randomly selected in each village/urban cluster, and finally, individuals of target age were randomly selected within each household. This procedure generally assured an equal representation of genders. In clusters where it yielded a gender imbalance, the underrepresented gender was over-sampled. In each province, rural and urban areas were sampled separately. To allow for a reasonable representation of different ethnic groups in rural areas, where the Kyrgyz largely predominate, ethnic minorities were over-sampled by making the probability of selection of primary sampling units 
(villages) proportional to the size of the non-Kyrgyz population (i.e., the larger the share of non-natives, the higher is the probability that the settlement will feature in the sample). Due to the specific sampling strategy and the unbalanced geographic distribution of ethnic groups in Kyrgyzstan, the survey is not representative of the rural population of Northern Kyrgyzstan or of the country as a whole, but it provides unique information on the demographic behavior of young Europeans and Asians in the surveyed areas.

The survey contains retrospective information on each respondent's educational, employment, and migration history, his/her record of marriage and childbearing, as well as other individual socio-economic and demographic characteristics; all events are identified with the accuracy of a month. With a remarkably low non-response rate of some six percent, counting both refusers and people not at home, the effective sample consists of 756 men and 772 women; the total sample size is 1528. Respondents' ages at interview range between 18 and 29 years, with a mean age of 23.1 (23.4 for women and 22.8 for men). A total of 29 percent of the respondents had a child at the time of survey; 38 percent had experienced a migration past age 15 .

In our analyses, we focus on the event of first childbirth and use multiplicative intensity-regression (proportional-hazard) models to analyze the propensity to become a parent. Computation is based on the number of first births (434 occurrences) as reported by the respondents, and the respective exposure times under risk of becoming a parent. The basic time variable is the number of months elapsed since the respondent reached age 15 .

The composition of our study population is presented in Table 1. It contains firstbirth occurrences and exposure times as childless, by each of the variables we apply in our modeling (next, these variables are described in more detail). We have defined three time-constant and seven time-varying covariates in order to test our main hypotheses and to study the associations of various migration and other characteristics with the propensity to become a parent. Note that the exposures refer to the number of months as childless counted from age 15 and the information on migration characteristics refer to the time after any first migration past age 15 - until the occurrence of a first birth or censoring. Censoring may occur either at the time of interview or at the time of a first migration abroad (as reported by persons who have re-migrated to Kyrgyzstan). 
Nedoluzhko \& Andersson: Migration and first-time parenthood: Evidence from Kyrgyzstan

Table 1: Sample composition for the analysis of first-birth risks in Northern Kyrgyzstan, 1990-2005

\begin{tabular}{|c|c|c|c|c|}
\hline & \multicolumn{2}{|c|}{ Exposures (months) } & \multicolumn{2}{|c|}{ Occurrences (first births) } \\
\hline & $\mathbf{N}$ & $\%$ & $\mathbf{N}$ & $\%$ \\
\hline \multicolumn{5}{|l|}{ Time-constant covariates } \\
\hline \multicolumn{5}{|l|}{ Gender } \\
\hline Man & 65,579 & 53.0 & 112 & 25.8 \\
\hline Woman & 58,092 & 47.0 & 322 & 74.2 \\
\hline \multicolumn{5}{|l|}{ Ethnicity } \\
\hline European & 42,711 & 34.5 & 141 & 32.5 \\
\hline Russified Asian & 43,454 & 35.1 & 122 & 28.1 \\
\hline Non-russified Asian & 37,506 & 30.3 & 171 & 39.4 \\
\hline \multicolumn{5}{|l|}{ Place of birth } \\
\hline Bishkek & 25,755 & 20.8 & 65 & 15.0 \\
\hline Medium/small town & 36,150 & 29.2 & 117 & 27.0 \\
\hline Village & 56,373 & 45.6 & 231 & 53.2 \\
\hline Abroad & 5393 & 4.4 & 21 & 4.8 \\
\hline \multicolumn{5}{|l|}{ Time-varying covariates } \\
\hline \multicolumn{5}{|l|}{ Age } \\
\hline $15-18$ & 54,660 & 44.2 & 33 & 7.6 \\
\hline $18-20$ & 29,211 & 23.6 & 101 & 23.3 \\
\hline $20-22$ & 19,532 & 15.8 & 106 & 24.4 \\
\hline $22-24$ & 11,446 & 9.3 & 112 & 25.8 \\
\hline $24-26$ & 5881 & 4.8 & 56 & 12.9 \\
\hline $26-29$ & 2941 & 2.4 & 26 & 6.0 \\
\hline \multicolumn{5}{|l|}{ Employment } \\
\hline Employed & 25,244 & 20.4 & 138 & 31.8 \\
\hline Non-employed & 98,427 & 79.6 & 296 & 68.2 \\
\hline \multicolumn{5}{|l|}{ Education } \\
\hline In secondary education & 43,045 & 34.8 & 11 & 2.5 \\
\hline In vocational or higher education & 26,432 & 21.4 & 62 & 14.3 \\
\hline \multicolumn{5}{|l|}{ Out of education: } \\
\hline Basic secondary & 6281 & 5.1 & 33 & 7.6 \\
\hline General secondary or vocational & 43,724 & 35.4 & 289 & 66.6 \\
\hline Higher & 4189 & 3.4 & 39 & 9.0 \\
\hline \multicolumn{5}{|l|}{ Destination of migration } \\
\hline No migration after age 15 & 98,899 & $(80.0)$ & 239 & $(55.1)$ \\
\hline Migrated to Bishkek & 13,857 & 56.0 & 75 & 38.5 \\
\hline Migrated to medium/small town & 7064 & 28.5 & 61 & 31.3 \\
\hline Migrated to village & 3851 & 15.6 & 59 & 30.3 \\
\hline
\end{tabular}


Table 1: (Continued)

\begin{tabular}{|c|c|c|c|c|}
\hline & \multicolumn{2}{|c|}{ Exposures (months) } & \multicolumn{2}{|c|}{ Occurrences (first births) } \\
\hline & $\mathbf{N}$ & $\%$ & $\mathbf{N}$ & $\%$ \\
\hline \multicolumn{5}{|l|}{ Time since migration } \\
\hline No migration after age 15 & 98,899 & $(80.0)$ & 239 & $(55.1)$ \\
\hline 1st year since migration & 5715 & 23.1 & 44 & 22.6 \\
\hline 2nd year since migration & 4615 & 18.6 & 31 & 15.9 \\
\hline 3rd year since migration & 3662 & 14.8 & 25 & 12.8 \\
\hline 4 th -5 th years since migration & 5234 & 21.1 & 39 & 20.0 \\
\hline $5+$ years since migration & 5546 & 22.4 & 56 & 28.7 \\
\hline \multicolumn{5}{|l|}{ Cause of migration } \\
\hline No migration after age 15 & 98,899 & $(80.0)$ & 239 & $(55.1)$ \\
\hline Moved with parents/family & 3376 & 13.6 & 23 & 11.8 \\
\hline Marriage & 1277 & 5.2 & 60 & 30.8 \\
\hline Work & 4054 & 16.4 & 30 & 15.4 \\
\hline Study & 13,449 & 54.3 & 68 & 34.9 \\
\hline Other reasons & 2616 & 10.6 & 14 & 7.2 \\
\hline \multicolumn{5}{|l|}{ Marital status } \\
\hline Not married & 116,623 & 94.3 & 97 & 22.4 \\
\hline Married & 7048 & 5.7 & 337 & 77.6 \\
\hline
\end{tabular}

Source: Calculations based on the survey 'Marriage, Fertility, and Migration in Kyrgyzstan', 2005.

\subsection{Covariates}

\subsubsection{Migration and migration-related variables}

We define migration as a residential change for a period of at least six months that is associated with the crossing of an administrative border of a settlement. In our firstbirth models, we aim at studying the associations of the various characteristics of any first migration past age 15 with the propensity to become a parent. (For 63\% of respondents who reported such migration experience, there was only one adulthood migration.) To study the effect of such migration on first-birth fertility, we have experimented with a number of covariates, among them the following: (1) place of birth; (2) place of residence at age 15; (3) destination of migration; (4) time since migration; and (5) cause of migration. Table 1 shows the different categories of the four categorical covariates that we have kept for our final modeling. Going beyond the conventional rural-urban dichotomy in migration research, we distinguish between four types of settlements for areas of origin: the capital Bishkek, medium/small town, village, and abroad. We do not use the latter category for areas of destination as observations are censored at the time of any first emigration. 


\subsection{2 'Ethnicity'}

We put the word 'ethnicity' within quotation marks because of our broad definition of it and because of the general ambiguity of this concept. Based on respondents' selfreported ethnic origin and the language they speak most of the time outside home, we define three ethno-cultural groups: 'Europeans', 'russified Asians', and 'non-russified Asians'. We classified individuals of Asian origin who speak Russian as 'russified Asian' and those who speak other languages (mostly Kyrgyz) as 'non-russified'. The category of 'Europeans' includes Russians (91\%) and other respondents of European origin. The study population is relatively evenly distributed between the three ethnocultural groups, reflecting the fact that Europeans were over-sampled in the survey.

\subsubsection{Educational characteristics}

Our survey data provide information on each stage of the respondent's educational career. Based on this information, we have constructed a time-varying covariate that allows us to track first-birth patterns during periods in which respondents are in and out of education, respectively. For our educational covariate, we define five levels that reflect both the educational enrolment and level attained.

\subsubsection{Employment}

We use two levels for our employment covariate, namely 'employed' and 'not employed'. We have coded respondents as employed irrespective of whether they were in a full-time or part-time job. The category 'employed' also includes periods of temporary employment, and studying individuals can occasionally be coded with both statuses, i.e. 'employed' and 'in education' if they have reported any simultaneous work (including seasonal work and self-employment) for which they received money or other recompense. Table 1 reveals a relatively low fraction of exposure months in employment, which is mostly due to the fact that young people are in education most of the time prior to becoming a parent.

\footnotetext{
${ }^{5}$ Women who reported to be pregnant or to have given first birth as the reason for interrupting work are coded as 'employed' from the start of employment until the occurrence of that birth.
} 


\subsubsection{Marital status}

The data at our disposal provide information on marital histories from which we have constructed a time-varying covariate with two levels, namely 'married' and 'not married'. The latter category includes single, divorced, separated, and widowed people. We have grouped all non-married individuals together because the fraction of separated and widowed in the young population of our study is very small. As regards non-marital unions, our data are incomplete, thus we cannot account for such histories in our modeling.

\section{Model results}

The results of our main-effects models are presented in Table 2, which provides the relative risks of first-time parenthood for young people in Kyrgyzstan by the different categories of the covariates we presented in Table 1. (At this stage, marital status is not included in our modeling, but it will be discussed in Section 7.4.) The table also provides p-values from tests of non-effects of included variables. The number of survey respondents in our data admittedly is quite small, but most variables still have significant effects, i.e., in most cases, the probabilities of random effects are low. We use these p-values as guidance when judging the meaningfulness of estimated patterns in first-birth risks, but we do not let high p-values alone make us dismiss patterns of associations that otherwise would appear meaningful to us. In what follows, we discuss the different associations we find between our key variables and the propensity to become a parent in Kyrgyzstan.

Table 2: Relative risks of entry into parenthood, young women and men in Kyrgyzstan, 1990-2005

\begin{tabular}{lrrrrrr}
\hline & \multicolumn{2}{c}{ Model 1 } & \multicolumn{2}{c}{ Model 2 } & \multicolumn{2}{c}{ Model 3 } \\
& Relative risk & P-value & Relative risk & P-value & Relative risk & P-value \\
\hline Age & & 0.000 & & 0.000 & & 0.000 \\
$15-18$ & 1 & & 1 & & 2.56 & \\
$19-20$ & 2.65 & & 2.65 & & 3.89 & \\
$21-22$ & 4.00 & & 4.19 & & 6.56 & \\
$23-24$ & 6.78 & & 7.32 & & 6.51 & \\
$25-26$ & 6.72 & & 7.46 & & 6.76 & \\
$27-29$ & 6.68 & & 7.64 & & & \\
\hline
\end{tabular}


Nedoluzhko \& Andersson: Migration and first-time parenthood: Evidence from Kyrgyzstan

Table 2: $\quad$ (Continued)

\begin{tabular}{|c|c|c|c|c|c|c|}
\hline & \multicolumn{2}{|c|}{ Model 1} & \multicolumn{2}{|c|}{ Model 2} & \multicolumn{2}{|c|}{ Model 3} \\
\hline & Relative risk & P-value & Relative risk & P-value & Relative risk & P-value \\
\hline Gender & & 0.000 & & 0.000 & & 0.000 \\
\hline Man & 1 & & 1 & & 1 & \\
\hline Woman & 4.06 & & 4.02 & & 3.62 & \\
\hline Ethnicity & & 0.000 & & 0.000 & & 0.000 \\
\hline European & 1 & & 1 & & 1 & \\
\hline Russified Asian & 0.68 & & 0.68 & & 0.70 & \\
\hline Non-russified Asian & 1.27 & & 1.25 & & 1.22 & \\
\hline Employment & & 0.031 & & 0.039 & & 0.070 \\
\hline Employed & 1 & & 1 & & 1 & \\
\hline Non-employed & 1.27 & & 1.26 & & 1.23 & \\
\hline Education & & 0.000 & & 0.000 & & 0.000 \\
\hline In secondary education & 1 & & 1 & & 1 & \\
\hline In vocational or higher education & 2.77 & & 2.66 & & 3.01 & \\
\hline Out of education: & & & & & & \\
\hline Basic secondary & 8.54 & & 8.14 & & 8.38 & \\
\hline General secondary or vocational & 7.47 & & 7.15 & & 7.18 & \\
\hline Higher & 6.27 & & 6.34 & & 7.20 & \\
\hline Place of birth & & 0.792 & & 0.854 & & 0.816 \\
\hline Bishkek & 1 & & 1 & & 1 & \\
\hline Medium/small town & 1.00 & & 1.00 & & 0.98 & \\
\hline Village & 0.91 & & 0.92 & & 0.91 & \\
\hline Abroad & 0.86 & & 0.87 & & 0.83 & \\
\hline Destination of migration ${ }^{\mathrm{a}}$ & & 0.000 & & 0.000 & & 0.353 \\
\hline No migration after age 15 & 0.79 & & 0.78 & & 0.66 & \\
\hline Migrated to Bishkek & 1 & & 1 & & 1 & \\
\hline Migrated to medium/small town & 1.41 & & 1.39 & & 1.20 & \\
\hline Migrated to village & 2.44 & & 2.28 & & 1.50 & \\
\hline Time since migration ${ }^{\mathrm{a}}$ & & & & 0.437 & & 0.998 \\
\hline No migration after age 15 & & & 1 & & 1 & \\
\hline 1st year since migration & & & 1.29 & & 0.97 & \\
\hline 2nd year since migration & & & 1.13 & & 1.03 & \\
\hline 3rd year since migration & & & 1.05 & & 1.08 & \\
\hline 4 th -5 th years since migration & & & 0.91 & & 1.04 & \\
\hline $5+$ years since migration & & & 0.81 & & 0.97 & \\
\hline Cause of migration ${ }^{\mathrm{a}}$ & & & & & & 0.000 \\
\hline No migration after age 15 & & & & & 1.26 & \\
\hline Moved with parents/family & & & & & 1 & \\
\hline Marriage & & & & & 3.39 & \\
\hline Work & & & & & 1.07 & \\
\hline Study & & & & & 0.89 & \\
\hline Other reasons & & & & & 0.97 & \\
\hline Log-likelihood & -2523.48 & & -2521.07 & & -2501.78 & \\
\hline
\end{tabular}

Source: Calculations based on the survey 'Marriage, Fertility, and Migration in Kyrgyzstan', 2005.

${ }^{\text {a }}$-Migration experience refers to first migration past age 15 . 


\subsection{Migration experience and first-birth fertility}

In our modeling, we have applied a step-wise approach where we add different dimensions of migration experience to our models in a pre-determined order. We start by including respondent's residence of origin and 'destination of migration' into our model. We subsequently add 'time since migration' and 'cause of migration' to the models. As the inclusion of a new covariate may alter the estimated effects of previously included factors, our procedure allows us to detect interrelations in the way the various representations of migration experience are associated with childbearing behavior.

We have elaborated with different representations of the type of the previous and current residence. It appears that neither 'place of birth' nor 'place of residence at age 15 ' are associated with first-birth risks. We include the former variable in our models, nevertheless. In contrast, the destination of a first migration turns out to be strongly associated with the propensity to become a parent. First-birth risks are highest for migrants to villages and lowest for those who had moved to Bishkek, i.e., the risk decreases with increasing settlement size at destination. A possible explanation is that migration to urban settlements in general and the capital in particular often is caused by the desire to find a (better) job or to obtain education beyond levels attainable in rural areas. In such cases, postponement of childbearing may be reasonable. However, we also note that, in general, the propensities to first-time parenthood are higher for migrants than they are for non-migrants, and this regardless of the destination of the move (see Model 1 of Table 2).

Model 3 of Table 2 reveals that migration caused by marriage increases the firstbirth propensity past migration (which should come as no surprise) and that this tendency entirely explains the elevated fertility that is observed during the first two years following migration (see Model 2). Like other studies that fully account for time since migration, Model 2 reveals elevated fertility shortly after a move (though in our case, this pattern is not statistically significant). The addition of our information to selfreported causes of migration in Model 3 picks up the effect of marriage formation and makes the effect of time since migration vanish. A further demonstration of the duration effects of Model 2 is provided in Table 3, where we display the interaction effect of 'time since migration' and 'gender'. 
Nedoluzhko \& Andersson: Migration and first-time parenthood: Evidence from Kyrgyzstan

Table 3: Relative risks of entry into parenthood in Kyrgyzstan: risk by time since first migration past age 15 for women and men

\begin{tabular}{lrr}
\hline Time since migration & Men & Women \\
\hline No migration after age 15 & 1 & 1 \\
1st year since migration & 1.80 & 3.37 \\
2nd year since migration & 2.31 & 2.81 \\
3rd year since migration & 2.61 & 2.48 \\
4th-5th years since migration & 1.72 & 2.35 \\
5+ years since migration & 2.48 & 1.72 \\
\hline
\end{tabular}

Source: Calculations based on the survey 'Marriage, Fertility, and Migration in Kyrgyzstan', 2005.

Note: Controlled for age, ethnicity, employment, education, place of birth, and destination of migration.

$\mathrm{P}$-value of test of interaction $=0.54$.

The interaction is by no means statistically significant, but it still indicates that it is the first-birth fertility of women that appears strongly elevated shortly after migration, while the first-birth risks of men rather peak at some years later after their migration. This suggests that men often act as forerunners in couple migration, with women subsequently joining their partner for reasons of marriage and family formation. A similar gender-specific pattern of migrant fertility has been demonstrated by Toulemon and Mazuy (2004) for foreign-born immigrants to France.

We have experimented with several other interactions as well and found that recent migration driven by the motive to find or change a job or to pursue education is related to somewhat reduced parenthood propensities shortly after migration. This can be seen in the interaction of time since migration and reason behind migration (results not shown; $\mathrm{p}$-value $=0.096$ ), and it can perhaps be taken as evidence of some disruptive or delaying influences of this kind of migration on first-birth fertility. (As expected, marriage migration shows up in this interaction with elevated fertility at short durations since resettlement.) We have further experimented with various combinations of ruralurban origins and destinations, as well as with the inclusion of a time-varying covariate reflecting the current place of residence, but found no support for our hypotheses on the importance of 'overcoming social distance' or the effects of early socialization on firstbirth behavior. 


\subsection{Ethno-cultural differentials in first-birth behavior}

Our analysis indicates that the 'russified' group of Asians is significantly different from the other two ethno-cultural groups of our study as concerns their first-birth behavior, thus the group does not occupy an intermediate position between the other two (see Table 2). They have the lowest risk of entry into parenthood: about 30 percent lower than among the 'Europeans' and 50 percent lower than among the 'non-russified Asians', i.e., they tend to exhibit a reproductive strategy that often entails postponed parenthood. An interaction between age and ethnicity (not shown; $p$-value $=0.009$ ) reveals that the first-birth risks of Europeans peak at lower ages than for Asians. This finding contradicts the assumption (based on observed differences in total fertility) that early family formation dominates among Asians in general in Kyrgyzstan. However, the finding is supported by census data, these show that Russian women indeed have a lower age at first birth than the aggregated group of Kyrgyz women (23.4 versus 23.7 years). A similar pattern of persistently early entry into parenthood in a population with very low fertility has been observed for Ukraine (cf. Perelli-Harris 2005).

\subsection{Education, employment, and first-time parenthood}

Our model results (see Table 2) show that those who are still in education have a much lower propensity to become a parent than those who are not enrolled in schooling, i.e., the incompatibility of educational enrolment and parenthood reported for so many other countries (e.g., Edwards 2002, Baizan et al. 2004) applies to Kyrgyzstan as well. The level of educational attainment itself seems to be slightly positively associated with deferred parenthood, with respondents that have completed only basic secondary education having the highest first-birth risks.

The association of labor-force participation with the timing and level of fertility is important to consider (cf. Becker 1981, Hoem and Hoem 1989, Bernhardt 1993, Hoem 1993, Andersson 2000) and our results for Kyrgyzstan first indicate that non-employed individuals have first-birth risks that are about 25 percent higher than the corresponding risks for the employed (see Table 2). The finding may be surprising; however an interaction between 'employment' and 'gender' reveals that the patterns are entirely different between women and men. The interaction is presented in Table 4, which shows that the first-birth risks of employed men are higher while the opposite holds for women. It demonstrates the existence of non-symmetrical gender roles in Kyrgyzstan, and shows that among women employment tends to be related to postponed parenthood. The results indicate that women's employment and parenthood are competing activities, 
something that tends to hold in societies that fully accord the responsibility of childrearing to the mother.

Table 4: Relative risks of entry into parenthood in Kyrgyzstan: risk of employed relative to that of non-employed for women and men

\begin{tabular}{lrr}
\hline Employment status & Men & Women \\
\hline Non-employed & 1 & 1 \\
Employed & 1.51 & 0.57 \\
\hline
\end{tabular}

Source: Calculations based on the survey 'Marriage, Fertility, and Migration in Kyrgyzstan', 2005.

Note: Controlled for age, ethnicity, education, place of birth, and migration.

$\mathrm{P}$-value of test of interaction $=0.000$.

A further interesting finding is the three-way interaction of 'employment', 'gender', and 'ethnicity' (results not shown). It indicates that the positive effect of a man's employment on his first-birth fertility differs by his ethno-cultural belonging. For European men, the propensity to have a child appears to be reduced by more than 60 percent by not being established in the labor market, while for Asian men this effect is much more moderate - first-birth risks for the non-employed are only 9-12\% lower than for those employed. The latter finding could possibly be seen as a reflection of the importance of family support, i.e., Asians traditionally have more extended families that provide help for members in need.

\subsection{Marital status}

Last, we have experimented with the inclusion into our models of a variable for marital status. It should be noted that marriage remains the prevailing form of co-residential union in Kyrgyzstan. In our data, around four fifths of those in union at the time of interview were also officially married, something that conforms reassuringly well with figures on young adults from the National Statistical Committee (Kudabaev et al. 2004). Since marriage is an intervening factor between our main covariates and firstbirth fertility, it is debatable to what extent it makes sense to include into our models a factor for marital status. We have not included it in our main effects models in Table 2. Nevertheless, we provide an account of the impact of such inclusion into a simplified version of our models in an Appendix Table to this article. It reveals that the risk of becoming a parent is 30 times higher for respondents in marital union than for the nonmarried. The introduction of marital status diminishes the effects of all other covariates and significantly improves the statistical fit of the model. 


\section{Reflections}

The present study has provided new insights into the family-formation dynamics of young women and men in post-Soviet Kyrgyzstan. It adds to the sparse knowledge on the role of socio-demographic and other characteristics in childbearing behavior in Kyrgyzstan in general, and on the interplay of migration and family formation in particular. In our empirical analyses, we tested various hypotheses about the interdependency between first-birth fertility and internal migration and the role of different socio-demographic factors in the propensity to become a parent. For example, we found support for our hypothesis on the deterring effect of educational enrolment on first-birth fertility, but there was no strong association between the educational level and the fertility of those who have completed education. As expected, marital status is very strongly linked with fertility and women become parents at earlier ages than men. We found clear gender-asymmetrical associations between the employment status and first-birth fertility, indicating that male employment tends to enhance the propensity to become a father while female employment, by contrast, is incompatible with first-time motherhood. In terms of ethno-cultural differences in first-birth behavior, we found that 'russified Asians' have the strongest tendency to delay parenthood while their 'nonrussified' compatriots have the highest first-birth rates.

The main focus of our study, however, is on the association of first-time parenthood with migration experience. In this section, we discuss our findings in the light of our migration-related hypotheses. We formulated our hypotheses based on the general literature on migration and fertility, this literature stipulates various assimilation, adaptation, disruption, and selection effects of migration on childbearing. With our data at hand, we are best situated to study short-term effects of a migration event on subsequent first-birth fertility, and we find support for the notion that in many cases migration and first-time parenthood are best viewed as interrelated events. In general, our findings on the link between migration experience and first-time parenthood underline the necessity for analysts to have access to proper duration data on the time elapsed since any migration event and likewise on the reasons for the moves. In our study, we found evidence of short-term enhancing migration effects on fertility past migration as well as tentative evidence of some disruptive effects. The different patterns correspond to our expectations: Migration motivated by marriage is related to increased first-birth risks and fully explains the elevated childbearing propensities of migrants in general during the first few years following resettlement; migration driven by the motive to find a job or receive education is related to slightly reduced propensities to become a parent. The enhancing effect on fertility rates of marriage-related migration tends to dominate over the disruptive effects of other types of migration. 
Our finding that migration motivated by marriage tends to be related to elevated first-birth fertility is not surprising in itself. Nevertheless, our access to such subjective information as self-reported causes of moves in combination with other retrospective data on migration and family formation histories allows us to gain much deeper insights into the nature of different general aspects of the interrelation between migration and fertility than what we would otherwise have been able to provide. Findings that in the absence of better data mainly would have formed the basis for speculation and formulation of hypotheses now can stand as they are: The first-birth fertility of migrants is elevated shortly after migration because migration motivated by family formation is associated with elevated parenthood risks. Similar general duration-specific effects of migration on first-birth fertility have been observed for many different types of migrants (cf. Andersson 2004, Toulemon and Mazuy 2004, Kulu 2006, Kulu and Vikat 2007). This suggests that there indeed are strong behavioral regularities in how people tend to locate their family-demographic vital events relative to that of a migration, with childbearing being much more common shortly after a migration than at preparation of such activity. It also calls for a critical stand to various accounts of high fertility of different groups of migrants: Crude statistics on elevated migrant fertility may be more likely to reflect the interrelation between migration and family formation than any real high-fertility behavior.

This being said, our findings need to be put in their proper context, and there are several circumstances around marriage formation and couple dynamics in Kyrgyzstan that are likely to reinforce the patterns we find. For example, we find evidence of elevated female first-birth fertility shortly after resettlement, while that of men tends to peak at some years later into their migration. This is likely to reflect that men often act as forerunners in couple migration. In addition, there are features of gender-specific patterns in marriage migration that are more specific to Kyrgyzstan. The prevailing norms that a couple should live in the husband's house or in the house of his parents and the re-emergence during post-Soviet times of the practice of 'bride kidnapping' make reported migration of women more likely to be motivated by family formation, soon followed by the birth of a child. We have no information on further specific details of the circumstances surrounding marriage migration in our data, and we are aware that we need better ethnographic data on such issues to fully interpret our findings. This certainly points to the need for further research on patterns in family formation in Kyrgyzstan that specifically address issues of these kinds. Not only the prevalence of 'bride kidnapping' needs to be better mapped, but also the fact that the practice itself seems to be acceptable to large fractions of the population, pointing to the need for deeper insights into changing gender relations and attitudes towards family, migration, and couple dynamics in post-Soviet Kyrgyzstan. Many issues wait for rigorous 
examination and motivate further research based both on qualitative and quantitative techniques.

As regards our assumptions that the residential environment experienced during childhood plays a role in shaping individual reproductive behavior, we found no support for this kind of 'socialization' hypotheses. This may partly be due to the relatively small size of our data, which may not enable us to cover all aspects of geographic origins and destinations in the first-birth behavior of migrants at the same time. We do, however, find tentative support for the hypothesis based on arguments that migrants adapt their fertility behavior to the opportunities and constraints prevailing at destination. Our results indicate that first-birth propensities are highest for those who have moved to a village and lowest for migrants to the capital of the country. Evidently, those who move to urban areas and to Bishkek, the economic and educational center of Kyrgyzstan, are more likely than other migrants to postpone childbearing. This is not surprising, given the fact that a large fraction of these migrations were motivated by study activity (see Table 1), i.e., by a reason that is associated with deferred childbearing. Nevertheless, we still find that first-birth risks are higher for people who have moved than for those who have not (yet) done so, regardless of destination.

Another way to interpret differences in first-birth fertility by destination is that childbearing behavior is related to the goals that once determined the move. It focuses on the selectivity of migrants by the family-building strategies they intend to pursue: Migration to rural areas is more often than migration to cities motivated by family formation. As for many other demographic studies, it is difficult for us to make a proper distinction between the forces of selection and adaptation in shaping the childbearing behavior of migrants.

Our study has demonstrated the importance of marriage formation to both internal migration and first childbearing of young adults in Kyrgyzstan. We did not focus explicitly on the timing of marriage formation in these dynamics, as we regard marriage an intervening factor in the relationship between the two behaviors we wanted to study: those of migration and those of first-time parenthood. In future research, we want to place a greater emphasis on the intervening role of marriage formation in these dynamics. We have located some issues to be addressed and that are in need of additional data gathering. Based on our existing data, we intend to study in more detail the triangular link between migration, fertility, and marriage formation, accounting more thoroughly for the various interdependencies in the timing of the three demographic processes. 


\section{Acknowledgments}

The first author is grateful for financial support from the Deutscher Akademischer Austausch Dienst (DAAD) during her research stay at the Max Planck Institute for Demographic Research in winter of 2005/06, and to that Institute for having provided its facilities during her stay there. She extends her gratitude to Jan M. Hoem for having provided instructions to the methods applied in this study. In addition, we thank Victor Agadjanian for his permission to use data of the survey 'Marriage, Fertility, and Migration in Kyrgyzstan' and for comments on our study results. We thank the National Council for East European and Eurasian Research, USA, for the funding of that survey. Finally, we are grateful for helpful comments from two anonymous reviewers of Demographic Research and the Editorial crew of this Special Collection 6 of the online Journal. 


\section{References}

Agadjanian, V. 1999. Post-Soviet demographic paradoxes: Ethnic differences in marriage and fertility in Kazakhstan, Sociological Forum 14(3): 425-46.

Agadjanian, V., and Z. C. Qian. 1997. Ethnocultural identity and induced abortion in Kazakstan, Studies in Family Planning 28(4): 317-329.

Andersson, G. 2000. The impact of labour-force participation on childbearing behaviour: pro-cyclical fertility in Sweden during the 1980s and the 1990s, European Journal of Population 16(4): 293-333.

Andersson, G. 2004. Childbearing after migration: fertility patterns of foreign-born women in Sweden, International Migration Review 38(2): 747-774.

Andersson, G., and K. Scott. 2005. Labour-market status and first-time parenthood: the experience of immigrant women in Sweden, 1981-97, Population Studies 59(1): 21-38.

Baizan, P., A. Aassve, and F. Billari. 2004. The interrelations between cohabitation, marriage and first birth in Germany and Sweden, Population and Environment 25(6): 531-561.

Becker, G. 1981. A Treatise on the Family. Cambridge, MA: Harvard University Press.

Becker, C., E. Musabek, A. Seitenova, and D. Urzhumova. 2003. Short-term migration responses of women and men during economic turmoil: lessons from Kazakhstan, Eurasian Geography and Economics 44(3): 228-243.

Bernhardt, E. 1993. Fertility and employment, European Sociological Review 9(1): $25-42$.

Bondarskaya, G. 1978. Fertility in the USSR (Ethno-Demographic Aspect). Moscow: Statistica (in Russian).

Chattopadhyay, A., M. White, and C. Debpuur. 2006. Migrant fertility in Ghana: selection versus adaptation and disruption as causal mechanisms, Population Studies 60(2): 189-203.

Demakov, G. 1997. Population migration and its social consequences in Kazakhstan, Tsentralnaya Azia 4: 28-37 (in Russian).

Denisenko, M. 2004. Fertility in Kyrgyzstan, in Z. Kudabaev, M. Guillot and M. Denisenko (Eds.), Population of Kyrgyzstan. Bishkek: National Statistical Committee of the Kyrgyz Republic (in Russian), pp. 206-241. 
Nedoluzhko \& Andersson: Migration and first-time parenthood: Evidence from Kyrgyzstan

Edwards, M. 2002. Education and occupations: reexamining the conventional wisdom about later first births among American mothers, Sociological Forum 17(3): 423-443.

Falkingham, J. 2005. The end of the rollercoaster? Growth, inequality and poverty in Central Asia and the Caucasus, Social Policy and Administration 39(3): 340-360.

Farber, S., and B. Lee. 1984. Fertility adaptation of rural-to-urban migrant women: a method of estimation applied to Korean women, Demography 21(3): 339-345.

Finnäs, F. 1997. Social integration, heterogeneity and divorce. The case of the Swedishspeaking population in Finland, Acta Sociologica 40: 263-277.

Fletcher, J., and B. Sergeyev. 2002. Islam and intolerance in Central Asia: the case of Kyrgyzstan, Europe-Asia Studies 54(2): 251-275.

Goldstein, S., and A. Goldstein. 1984. Inter-relations between migration and fertility their significance for urbanization in Malaysia, Habitat International 8(1): 93-103.

Hervitz, H. 1985. Selectivity, adaptation or disruption? A comparison of alternative hypotheses on the effects of migration on fertility: the case of Brazil, International Migration Review 19(2): 293-317.

Hiday, V. 1978. Migration, urbanization, and fertility in Philippines, International Migration Review 12(3): 370-385.

Hoem, B. 1993. The compatibility of employment and childbearing in contemporary Sweden, Acta Sociologica 36(2): 101-120.

Hoem, B., and J. Hoem. 1989. The impact of women's employment on second and third births in modern Sweden, Population Studies 43: 47-67.

Jones, S., and F. Grupp. 1987. Modernization, Values Changes and Fertility in the Soviet Union. Cambridge: Cambridge University Press.

Kleinbach, R., M. Ablezova, and M. Aitieva. 2005. Kidnapping for marriage ala kachuu in a Kyrgyz village, Central Asian Survey 24(2): 191-202.

Kudabaev, Z., M. Guillot, and M. Denisenko. 2004. (Eds.) Population of Kyrgyzstan. Bishkek: The National Statistical Committee of the Kyrgyz Republic (in Russian).

Kulu, H. 2005. Migration and fertility: competing hypotheses re-examined, European Journal of Population 21(1): 51-87. 
Kulu, H. 2006. Fertility of internal migrants: comparison between Austria and Poland, Population, Space and Place 12(3): 147-170.

Kulu, H., and A. Vikat. 2007. Fertility differences by housing type: The effect of housing conditions or of selective moves?, Demographic Research 17(26): 775-802. www.demographic-research.org/Volumes/Vol17/26/default.htm.

Kulu, H., A. Vikat, and G. Andersson. 2007. Settlement size and fertility in the Nordic countries, Population Studies 61(3): 265-285.

Kumskov, G. 2002. Patterns and Peculiarities of Contemporary Migration Processes in Kyrgyzstan. Bishkek: Kyrgyz-Russian Slavic University (in Russian).

Kumskova, N. 1983. Mechanisms of Population Mobility in Kirgizia. Frunze: Kyrgyzstan (in Russian).

Kumskova, N., G. Kumskov, and E. Ploskich. 2004. Contemporary Problems of Internal Migration in Kyrgyzstan. Bishkek: UNFPA in Kyrgyzstan (in Russian).

Lindstrom, D., and S. Giorguli Saucedo. 2002. The short- and long-term effects of US migration experience on Mexican women's fertility, Social Forces 80(4): $1341-1368$.

Lindstrom, D., and S. Giorguli Saucedo. 2007. The interrelationship of fertility, family maintenance, and Mexico-U.S. migration, Demographic Research 17(28): 821-858. www.demographic-research.org/Volumes/Vol17/28/default.htm.

Macisco, J., L. Bouvier, and R. Weller. 1970. The effect of labor force participation on the relation between migration status and fertility in San Juan, Puerto Rico, Milbank Memorial Fund Quarterly 48: 51-70.

Milewski, N. 2007. First child of immigrant workers and their descendants in West Germany: Interrelation of events, disruption, or adaptation?, Demographic Research 17(29): 859-896. www.demographic-research.org/Volumes/Vol17/29/ default.htm.

Nedoluzhko, L. 2000. Causes, peculiarities and consequences of migration processes in the Kyrgyz Republic during the transition period. Population and Development Research Monograph Series No. 7. Cairo: Cairo Demographic Center.

Nedoluzhko, L. 2003. Socio-economic reasons for fertility reduction, Vestnic 2(4): 24-30. Bishkek: Kyrgyz-Russian Slavic University (in Russian).

NSC of the Kyrgyz Republic. 2006. Men and Women of the Kyrgyz Republic. Bishkek: National Statistical Committee of the Kyrgyz Republic. 
Perelli-Harris, B. 2005. The path to lowest-low fertility in Ukraine, Population Studies 59(1): 55-70.

Ryspaev, S. 1972. Fertility in Kirgizia and its perspectives, in Regional Peculiarities of the USSR's Population Reproduction. Cheboksary: Ministry of Higher and Secondary Special Education of the RSFSR (in Russian).

Sarygulov, B. 2001. The Current Demographic Situation in Kyrgyzstan and Alternatives to its Development. Bishkek: UNFPA in Kyrgyzstan (in Russian).

Sifman, R. 1974. Fertility Dynamics in the USSR. Moscow: Statistica (in Russian).

Singley, S., and L. Landale. 1998. Incorporating origin and process in migrationfertility frameworks: the case of Puerto Rican Women, Social Forces 76(4): $1437-1464$.

Shuler, M., and Z. Kudabaev. 2004. Migration in Kyrgyzstan, in Z. Kudabaev, M. Guillot and M. Denisenko (Eds.), The Population of Kyrgyzstan. Bishkek: National Statistical Committee of the Kyrgyz Republic (in Russian), 281-303.

Stephen, E., and F. Bean. 1992. Assimilation, disruption and the fertility of Mexicanorigin women in the United-States, International Migration Review 26(1): $67-88$.

Subbotina, I. A. 1997. Russians in Kazakhstan: The migration situation on the eve and after the breakup of the USSR, in S. S. Savoskul (Ed.), Russians in the New Abroad: Migration Situation, Relocation, and Adaptation in Russia. Moscow: Institute of Ethnology of the Russian Academy of Sciences (in Russian), pp. 154-175.

Tishkov, V. A. 1994. Russians in Central Asia, in V. I. Kozlov and E. A. Shervoud (Eds.), Russians in the Near Abroad. Moscow: Institute of Ethnology and Anthropology of the Russian Academy of Sciences (in Russian), pp. 140-149.

Toulemon, L., and M. Mazuy. 2004. Comment prendre en compte l'âge à l'arrivée et la durée de séjour en France dans la mesure de la fécondité des immigrants? Documents de travail 120, 2004. Paris: Institut national d'études démographiques.

World Bank. 2006. Country profiles: Kyrgyzstan. http://www.worldbank.org/.

Wetherell, C., and A. Plakans. 1997. Fertility and culture in Eastern Europe: a case study of Riga, Latvia, 1867-1881, European Journal of Population 13: $243-268$. 
Yavuz, S. 2006. Completing the fertility transition: third birth developments by language groups in Turkey, Demographic Research 15(15): 435-460. www.demographic-research.org/Volumes/Vol15/15/default.htm. 


\section{Appendix 1}

\section{Relative risks of entry into parenthood, young women and men} in Kyrgyzstan, 1990-2005

\begin{tabular}{|c|c|c|c|c|}
\hline & \multicolumn{2}{|c|}{ Model 1} & \multicolumn{2}{|c|}{ Model 2} \\
\hline & Relative risk & P-value & Relative risk & P-value \\
\hline Age & & 0.000 & & 0.000 \\
\hline $15-18$ & 1 & & 1 & \\
\hline 19-20 & 2.67 & & 1.92 & \\
\hline $21-22$ & 4.09 & & 2.09 & \\
\hline $23-24$ & 6.82 & & 2.80 & \\
\hline $25-26$ & 6.74 & & 2.35 & \\
\hline $27-29$ & 6.70 & & 2.34 & \\
\hline Gender & & 0.000 & & 0.000 \\
\hline Man & 1 & & 1 & \\
\hline Woman & 4.01 & & 1.76 & \\
\hline Ethnicity & & 0.000 & & 0.102 \\
\hline European & 1 & & 1 & \\
\hline Russified Asian & 0.64 & & 0.75 & \\
\hline Non-russified Asian & 1.25 & & 0.88 & \\
\hline Employment & & 0.015 & & 0.149 \\
\hline Employed & 1 & & 1 & \\
\hline Non-employed & 1.31 & & 1.18 & \\
\hline Education & & 0.000 & & 0.000 \\
\hline In secondary education & 1 & & 1 & \\
\hline In vocational or higher education & 2.52 & & 2.06 & \\
\hline \multicolumn{5}{|l|}{ Out of education: } \\
\hline Basic secondary & 9.28 & & 6.15 & \\
\hline General secondary or vocational & 7.49 & & 3.36 & \\
\hline Higher & 5.77 & & 2.64 & \\
\hline Place of birth & & 0.670 & & 0.765 \\
\hline Bishkek & 1 & & 1 & \\
\hline Medium/small town & 0.89 & & 0.91 & \\
\hline Village & 0.83 & & 1.00 & \\
\hline Abroad & 0.84 & & 0.83 & \\
\hline Migration experience & & 0.000 & & 0.111 \\
\hline No migration after age 15 & 1 & & 1 & \\
\hline Migrated after age 15 & 1.81 & & 1.19 & \\
\hline Marital status & & & & 0.000 \\
\hline Not married & & & 1 & \\
\hline Married & & & 30.03 & \\
\hline Log-likelihood & -2534.83 & & -2088.49 & \\
\hline
\end{tabular}

Source: Calculations based on the survey 'Marriage, Fertility, and Migration in Kyrgyzstan', 2005. 